\title{
Investigating the Perceptions, Use, and Impact of Open Textbooks: A survey of Post-Secondary Students in British Columbia
}

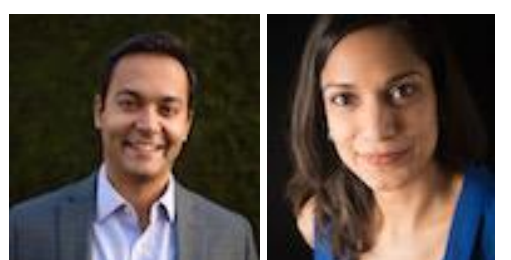

Rajiv Jhangiani ${ }^{1}$ and Surita Jhangiani ${ }^{2}$

${ }^{1}$ Kwantlen Polytechnic University, ${ }^{2}$ Justice Institute of British Columbia

\begin{abstract}
Unrelenting increases in the price of college textbooks have prompted the development and adoption of open textbooks, educational resources that are openly licensed and available to students free of cost. Although several studies have investigated U.S. students' perceptions and use of open textbooks, there are no published studies of this kind in Canada. Similarly, although the negative impact of commercial textbook costs on student outcomes is well documented within the United States, it is unknown whether these trends generalize to the Canadian post-secondary context. The present study involves a survey of 320 post-secondary students in British Columbia enrolled in courses using an open textbook during the Spring 2015, Summer 2015, and Fall 2015 semesters. The survey investigates students' textbook purchasing behaviours, including whether, where, and in what format(s) they purchase and access their required textbooks; the negative impact of textbook costs on their course enrolment, persistence, and performance; how they access and use their open textbook, including their format preferences and study habits; and their perceptions of their open textbook, including its quality and what features they like and dislike. The study's strengths and limitations are discussed, along with recommendations for future research.
\end{abstract}

Keywords: open educational resources, open textbooks, textbooks, perceptions, higher education, Canada

\section{Introduction}

The price of college textbooks in the United States has increased by $129 \%$ over the past fifteen years, a rate nearly four times that of inflation (U.S. Bureau of Labor Statistics, 2016). Although comparable 
Canadian data are not publicly available, the cost of textbooks in this smaller market is often higher due to a 10-15\% tariff imposed on imported books (Justice Laws Website, 2008), a piece of legislation that costs students an estimated \$30 million per year (Hall, 2013). As a result, students' educational choices are increasingly being driven by the question of whether they can afford their required course materials. Indeed, even the Financial Consumer Agency of Canada (2014), which advises postsecondary students to budget $\$ 800-\$ 1,000$ per year for textbooks and other required course materials, suggests that they should "share some resources with roommates or friends in the same program" if doing so is practical (Books and other course materials section, para. 2).

Unfortunately, there is a dearth of reliable and publicly-available data on student textbook spending in Canada. According to one survey of 1,350 university students across the country, the median undergraduate student spent $\$ 385$ during the Fall 2012 semester on required course materials (Usher, 2015). Although two-thirds of these respondents indicated that they had bought all of their required textbooks, the proportion of students doing so dropped significantly as the cost of their textbooks rose. For example, whereas $82 \%$ of students whose textbooks totalled less than $\$ 200$ bought all of their textbooks, only $48 \%$ of those whose textbooks totalled more than $\$ 800$ did so. Another survey, this one of 1,530 post-secondary students in Ontario, found that the median student spent between \$301-\$400 during the Spring 2009 semester on required course materials, with $47 \%$ of the sample agreeing somewhat or strongly with the statement "Buying the latest editions of textbooks is usually a waste of money" and only $19 \%$ endorsing the statement "Instructors generally check the price of course materials before deciding to require them" (Studentawards Inc. \& Stepwise Research, 2009).

South of the border, according to both a member survey conducted by the National Association of College Stores (2016) and interviews with a nationally-representative sample of 854 students conducted by Student Monitor (2016), actual spending on textbooks by U.S. students appears to have plateaued at an average of $\$ 600$ per year during the 2015/16 academic year (a significant decrease from the 2007/08 average of $\$ 701$; see Hill, 2015 for an analysis).

Taken together, the increase in textbook prices and the plateau in student spending logically suggests that a growing number of students are not purchasing all of their required textbooks new and at full price. Indeed, a recent survey of more than 20,000 students in Florida found that $64 \%$ had bought books from a source other than their campus store (e.g., Amazon), 49\% had opted to buy used textbooks from their campus store, $47 \%$ had rented print textbooks, $30 \%$ had rented digital textbooks, $24 \%$ had shared textbooks with classmates, and $39 \%$ had sold their used textbooks (Florida Virtual Campus, 2016). Another survey, this one of 1,600 students by the Book Industry Study Group (2013), found that $34 \%$ of respondents indicated that they or someone they knew had illegally downloaded their textbooks (an increase of 14\% from 2010). Although there have been several reports about the use of pirated textbooks by Canadian students (e.g., Lepore, 2013; Wallace, 2009), there are no publicly data available concerning the prevalence of this practice.

In cases where less expensive (or illegal) options for obtaining required course materials are not available, a growing proportion of students are simply opting to do without their required textbooks. Two-thirds of the respondents in the 2016 Florida student survey had not purchased at least one of their required course textbooks (Florida Virtual Campus, 2016), with 38\% indicating they earned a poor grade as a result. What is more, $48 \%$ of respondents had taken fewer courses, $26 \%$ had dropped a course, and $21 \%$ had withdrawn from a course, all reportedly due to cost. On average, respondents had 
purchased 2.6 "required" textbooks over their academic career that had not been used. Once again, there are no comparable Canadian data available.

It is for all of these reasons that faculty at colleges and universities across North America have been increasingly adopting open textbooks, textbooks that are available for free (in digital formats) or at low cost (in print format) and that are published with an open (e.g., Creative Commons) license that permits their unfettered reuse, retention, revision, remixing, and redistribution (Wiley, Bliss, \& McEwen, 2014). The development of these textbooks and their accompanying ancillary resources are funded by philanthropic organizations (e.g., the Hewlett Foundation), government (e.g., British Columbia Ministry for Advanced Education), universities (e.g., Portland State University), and professional bodies (e.g., Center for Computer-Assisted Legal Instruction). Worldwide, it is estimated that the adoption of open textbooks has collectively saved students $\$ 174$ million (Creative Commons, 2015).

Beyond individual faculty adoptions, a growing number of post-secondary institutions are building entire degree programs (so-called "Z degrees") in which all courses utilize open educational resources (OER), displacing the cost to students of traditional textbooks. A pioneering case is that of Tidewater Community College, which launched a textbook-free Associate of Science in Business Administration program in Fall 2013. By the end of its first year, the program had saved its 800 students $\$ 128,000$. What is more, fewer students enrolled in OER-based courses dropped their classes (Wiley, Williams, DeMarte, \& Hilton, 2016). These findings echo those of other studies that have discovered lower withdrawal rates, higher completion rates, and greater enrolment intensity following OER adoption (Hilton \& Laman, 2012; Hilton, Fischer, Wiley, \& William, 2016). Indeed, thirteen studies (with an aggregated sample of 119,720 students) that have investigated the impact of OER adoption on course performance found that $95 \%$ of these students have achieved the same or better outcomes when using OER (Hilton, 2016; Hilton et al., 2016; Wiley et al., 2016). Taken together, the OER efficacy literature suggests the significant cost savings to students that result from the adoption of open textbooks do not come at the cost of academic outcomes.

However, the question of the effectiveness of adopting an open textbook stands apart from questions concerning the experience of using an open textbook, including whether the experience is a positive one (compared against using a commercial textbook), how students interact with open textbooks, what features of open textbooks are most and least appealing to students, and how students rate the quality of open textbooks.

Several studies have investigated U.S. students' perceptions of OER (see Hilton, 2016, for a review). In one survey of 315 business students at Virginia State University, 95\% strongly agreed or agreed that the assigned OER were "easy to use" and $78 \%$ felt that these resources "provided access to more up-todate material than is available in my print textbooks" (Feldstein et al., 2012). Moreover, two-thirds of this sample indicated a preference for digital OER over commercial textbooks. In another study, approximately $80 \%$ of 910 students taking math courses that had adopted OER reported that the OER adequately supported their coursework, would recommend its use to their classmates, and wrote positive comments concerning its quality (Hilton, Gaudet, Clark, Robinson, \& Wiley, 2013). In yet another survey of 490 students across eight U.S. colleges found that $50 \%$ rated the quality of the adopted OER as equivalent to traditional, commercial textbooks whereas an additional $39 \%$ rated the quality as superior (Bliss, Robinson, Hilton, \& Wiley, 2013). A third of the sample supported these 
ratings with comments that touched on technical advantages (e.g., ability to easily search, change print size, and navigate the text), learning aids (e.g., embedded videos and quizzes), alignment of the text with lectures, cost savings, convenient access, and the quality of the writing. Finally, 524 students at Kansas State University using open or alternative textbooks rated the quality of these resources as above average (5.7 on a 7 point scale; Delimont, Turtle, Bennett, Adhikari, \& Lindshield, 2016). Corresponding ratings for their level of use of the resources and their preference for open or alternative educational resources were 5.5 and 5.7, respectively. Similar results have been found by a variety of other researchers (e.g., Bliss, Hilton, Wiley, \& Thanos, 2013; Gil, Candelas, Jara, Garcia, \& Torres, 2013; Lindshield \& Akhiri, 2013; Petrides, Jimes, Middleton-Detzner, Walling, \& Weiss, 2011; Pitt, Ebrahimi, McAndrew, \& Coughlan, 2013). However, once again, there are no published Canadian studies of students' perceptions of OER. Indeed, the only published report that investigated perceptions of OER quality in the Canadian context is a survey of post-secondary faculty in British Columbia, a majority of whom perceived OER to be comparable or superior to traditional, proprietary materials (Jhangiani, Pitt, Hendricks, Key, \& Lalonde, 2016).

Related to the perception of quality is the question of value and whether students who are assigned OER value these resources little or at least less than they would expensive commercial textbooks. However, despite the potential moderating impact of perceived value on textbook usage, to our knowledge, no published empirical study has yet explored this question, nor a related one about whether they would have preferred to purchase a commercial textbook (an inverse form of buyer's remorse).

Overall, relative to studies of OER efficacy and perceptions, comparatively few studies have investigated how students use open textbooks. In one survey of 94 university students, the median student reported using their "flexbook" once a week, accessing the text (97\%) and figures (87\%) far more than animations (30\%), videos (32\%), or links (32\%; Lindshield \& Adhikari, 2013). The same respondents indicated their liking of specific attributes of their book, with $69 \%$ liking that it was searchable, $56 \%$ liking that it was web-accessible, and $27 \%$ liking that it was updatable. In another survey, $52 \%$ of 132 community college students indicated a preference for their digital open textbook over traditional printed textbooks (another $31 \%$ indicated no preference), citing presentation, cost savings, and online accessibility as major reasons for this preference (Bliss et al., 2013). Finally, although these two surveys found great variation in students' use of web-based open textbooks (e.g., ranging from $90 \%$ to $26 \%$ ), they both found that PDF files are the most popular format among students who elect to download their open textbook.

\section{The Present Study}

Given the many important differences between the Canadian and U.S. post-secondary educational contexts (e.g., higher textbook costs and lower tuition fees in Canada), it is important to understand how Canadian students purchase and access their textbooks and the impact of textbook costs on their educational choices. Similarly, it is important to investigate whether the major findings of the literature on students' use and perceptions of OER replicate within the Canadian context. 
Accordingly, the present study has four objectives, all within the context of the post-secondary system in British Columbia, which is home to the BC Open Textbook Project ${ }^{1}$ (BCOTP) and leads Canada in the development, awareness, and adoption of open textbooks:

1. to investigate whether, where, and in what format(s) post-secondary students purchase and access their required textbooks,

2. to assess the impact of textbook costs on students' course enrolment, persistence, and performance,

3. to explore students' use of open textbooks, including how they access their textbooks and their textbook study habits, and

4. to explore students' perceptions of open textbooks, including what features they like and dislike and the monetary value they place on them.

\section{Method}

\section{Participants}

Participants were recruited by emailing known faculty adopters of open textbooks during the Spring 2015, Summer 2015, and Fall 2015 semesters and asking them to forward an email invitation to their students. The recruitment emails were distributed by BCcampus, the provincial organization responsible for managing the BCOTP and to whom each of the faculty adopters had chosen to report their adoption(s). Although it is unknown how many of the contacted faculty (some of whom were contacted thrice over the year) elected to forward the email invitation to their students and how many of their classes were fully subscribed, the sampling frame included a potential total of 4,370 students enrolled in 122 courses taught by 52 faculty at 15 institutions.

The email invitation included a link to an online consent form. Upon providing their consent, respondents were automatically redirected to the online survey. Both the informed consent form and the survey were hosted on Qualtrics online survey platform. At the end of the survey, respondents were given the opportunity to enter their email address into a draw to receive one of fifty $\$ 50$ gift certificates. This study was approved by the Research Ethics Board at Kwantlen Polytechnic University.

The final sample consisted of 320 undergraduate students ${ }^{2}$ enrolled in 19 courses at 12 B.C. postsecondary institutions that had adopted an open textbook. Assuming that all 4,370 students received the email invitation, this represents a response rate of $7.3 \%$ and a sampling error (based on a 95\% CI) of $5.3 \%$. The great majority of respondents were students at either teaching-intensive universities (46\%) or colleges (33\%), with the remainder at research-intensive universities (11\%), technical institutes (5\%), and a private graduate university (5\%).

Sixty-four percent of the sample identified as female, $52 \%$ reported that English is their second or subsequent language, and $35 \%$ identified as a visible minority. The median respondent was a first-year 
undergraduate student enrolled in three courses (the threshold for categorization as a full-time student), had enrolled in seven to nine courses over the previous 12 months (including the current semester), and had an average grade (across all of their undergraduate coursework) of $70-80 \%$. The sample represents a broad range of disciplines (see Figure 1). Most (81\%) respondents had never taken a course that was taught entirely or partly online. Only $31 \%$ of respondents were not currently employed, with $44 \%$ working more than 15 hours per week. Furthermore, $72 \%$ of those that were employed reported earning less than $\$ 500$ per week. Twenty-four percent of participants reported holding a student loan.

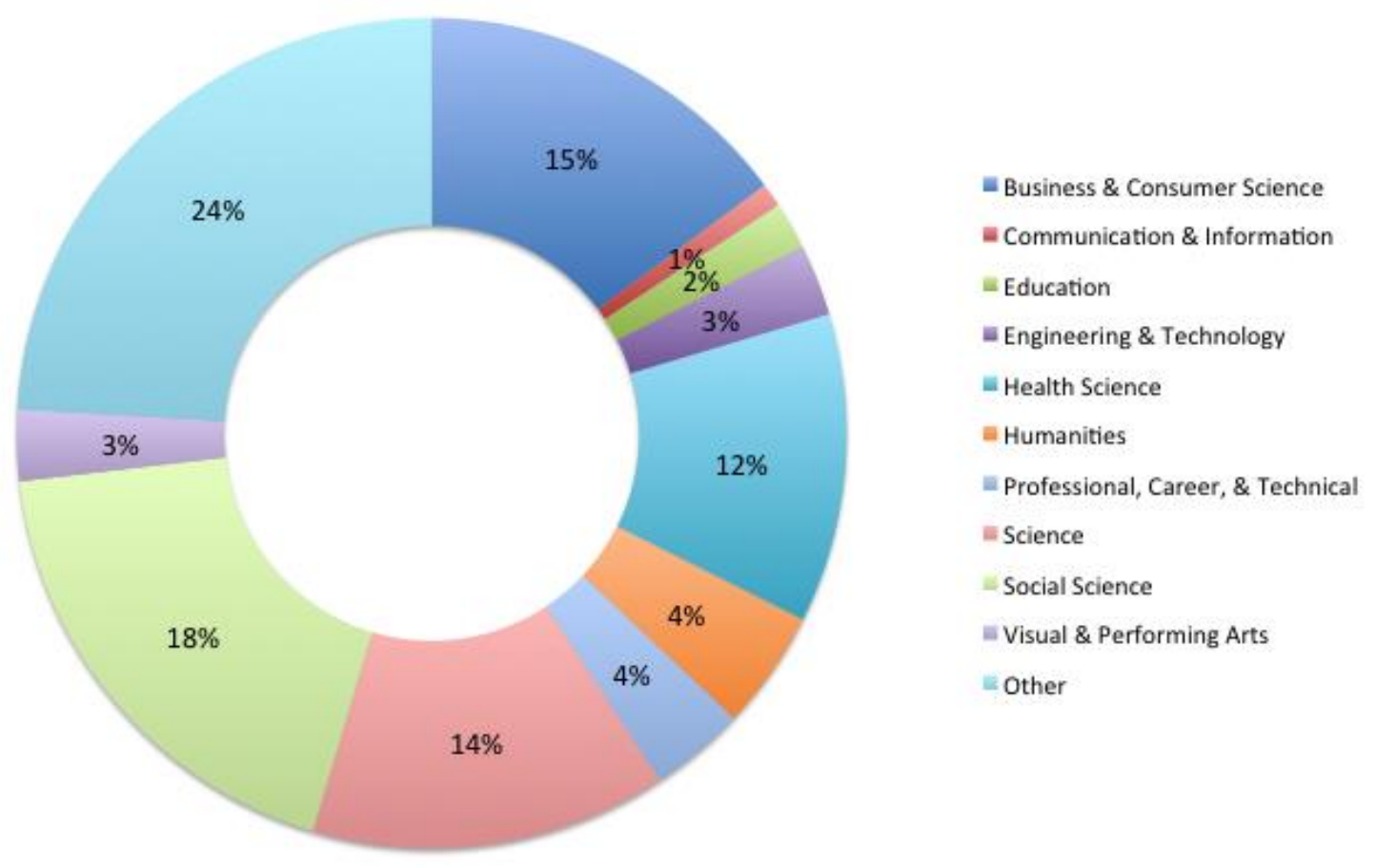

Figure 1. Respondents' primary area of study.

\section{Materials and Procedure}

The online survey included 37 close-ended and three open-ended questions and were grouped as follows.

Demographic information. Six questions about respondents' age, sex, ethnic minority status, level of employment, weekly income, and student loan status.

Educational background. Seven questions about respondents' current and previous undergraduate coursework, including the number of courses currently enrolled in, number of courses enrolled in during the previous 12 months, total credits of undergraduate coursework completed, enrollment in courses taught wholly or partially online, cumulative GPA, primary area of study, and institutional affiliation.

Impact of textbook costs. Four questions about respondents' spending on textbooks during the previous 12 months; whether, where, and in what format(s) they obtained their textbooks; 
and whether the cost of textbooks has influenced their course enrolment, persistence, and performance.

Current course. Four questions about the course in which they were currently enrolled that had adopted an open textbook, including the name of the course (open ended), their approximate interim grade, estimated overlap between textbook and lecture content, and estimated proportion of exam questions drawn from the textbook.

Current open textbook. Ten questions about the format(s) in which they accessed their open textbook, whether they printed it, the importance of its features (e.g., cost savings, immediate access) and permissions (e.g., to retain and redistribute), two open-ended questions about what they liked and disliked about it, a global rating of its overall quality, an estimated fair price for it (regardless of what they paid), their preference for commercial textbooks, preferred textbook format, and (in the case of respondents who indicated a dislike for digital textbooks) their reasons for disliking digital textbooks.

Study habits. Six questions about how much time respondents spend per week studying for their course, the proportion of weekly assigned readings they typically complete, how early and for how long they study for their course exams, how closely they read their textbook before an exam, and how often their instructor encourages them to read their textbook.

The median respondent took eight minutes to complete the survey. At the end of the survey, respondents were redirected to a separate form (not linked to their survey responses) where they were given the opportunity to enter into the draw.

\section{Results}

\section{Textbook Purchasing Behaviours}

The amount that respondents reported having spent on textbooks during the previous 12 months ranged from $\$ 0$ to $\$ 3,000(M=\$ 698, M d n=\$ 500, S D=\$ 540)$. In order to estimate the average amount spent by students on textbooks per course we used the following formula:

$$
\frac{\text { Average amount spent purchasing textbooks during the previous } 12 \text { months }}{\text { (Average number of credits enrolled in during the previous } 12 \text { months }-3)} \times 3
$$

This formula, which assumes that the courses in which respondents were assigned an open textbook carried an average of three credits, yields estimates of the mean (\$99.71) and median (\$71.43) amounts spent per course on textbooks. When asked to report the number of required textbooks that remained unused during their classes, some respondents reported this as a percentage $(M=50.75 \%$, $S D=27.36 \%, n=177)$ while others reported this as a number $(M=2.99, S D=2.57, n=116)$.

Over half of the respondents (54\%) reported not purchasing a required textbook at least once (see Figure 2). Bivariate correlations revealed that these individuals were more likely to hold a student loan $[r(307)=.16, p=.01]$ and be working more hours per week $[r(254)=.13, p=.05]$. 


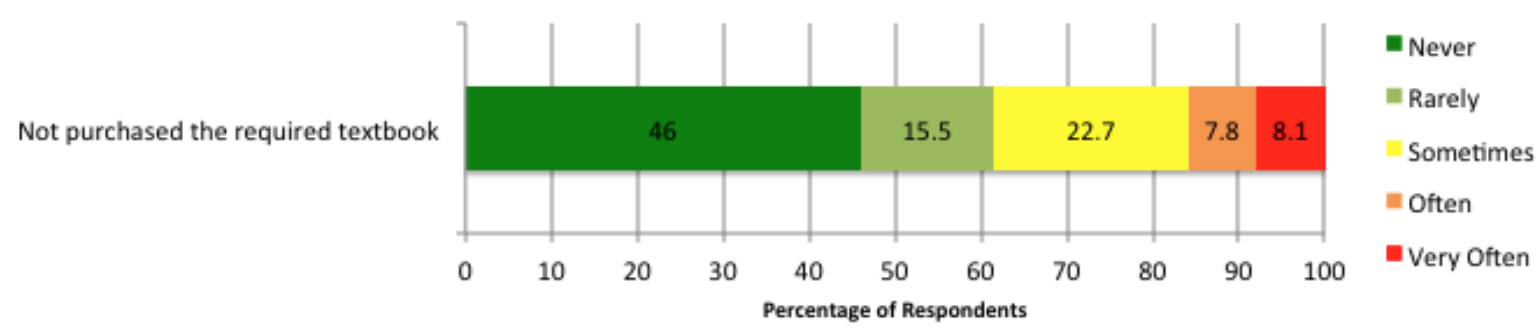

Figure 2. Frequency with which respondents do not purchase a required course textbook.

Respondents were slightly more likely to report purchasing their textbooks from a source other than their campus store (57\%) than purchasing used textbooks at their campus bookstore $(51 \%)$. Thirty percent of respondents reported downloading textbooks from the internet, $26 \%$ reported sharing their textbooks with classmates, $21 \%$ leased commercial e-textbooks (only $3 \%$ leased individual e-chapters), $10 \%$ used a reserve copy of the textbook at the university library, $7 \%$ rented textbooks in print format, and $4 \%$ rented textbooks in digital format. Just over half (52\%) of respondents reported selling their used textbooks. Once again, point biserial correlations revealed that these individuals were more likely to be working more hours per week $\left[r_{p b}(265)=.20, p=.001\right]$. Finally, only $18 \%$ reported not being influenced by the cost of textbooks (see Figure 3 ).

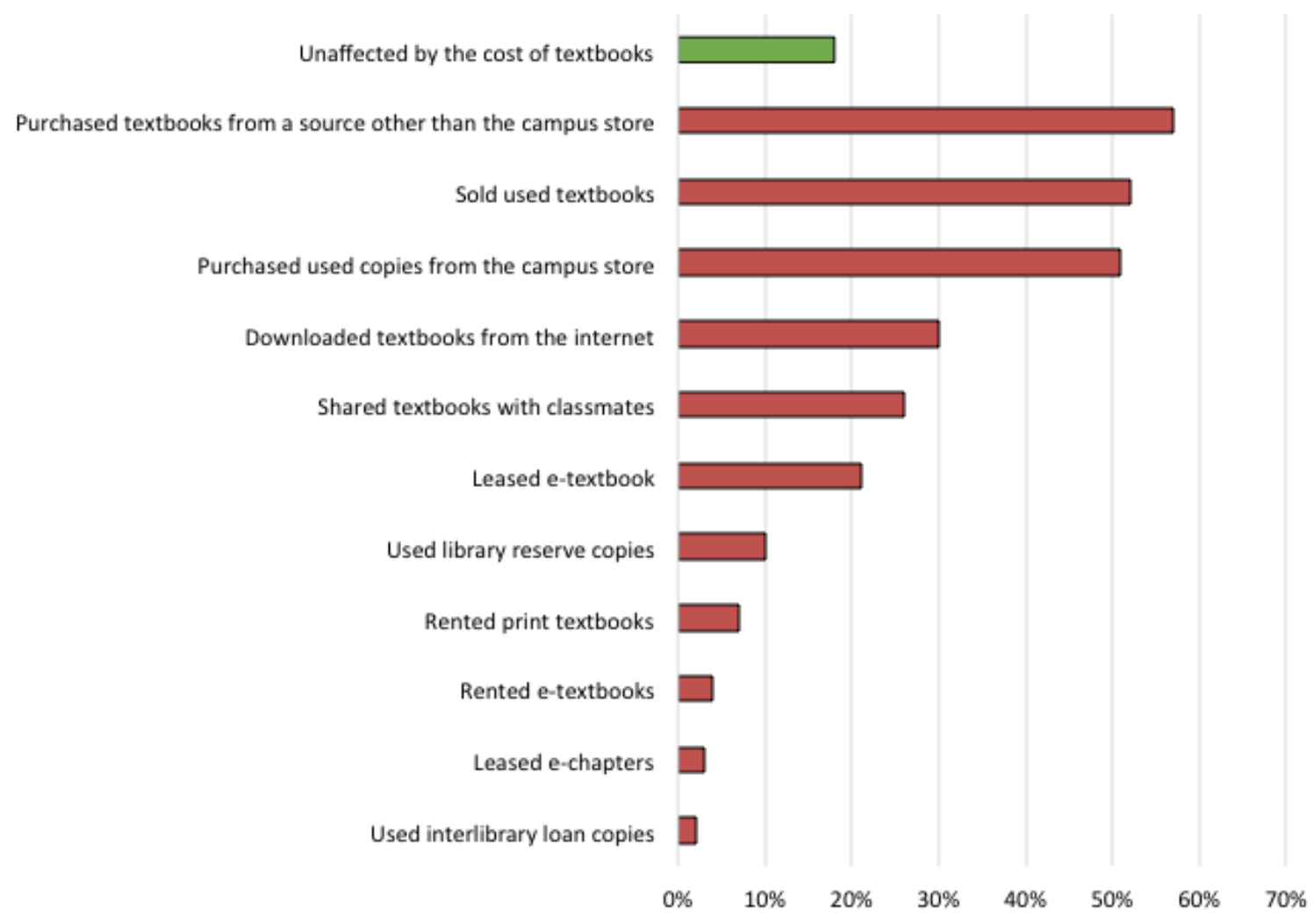

Figure 3. Impact of textbook costs on students' textbook purchasing behaviours.

\section{Impact of Textbook Costs on Course Outcomes}

When asked about how the cost of textbooks had influenced their course enrolment and persistence, $27 \%$ of respondents indicated that they had taken fewer courses, $26 \%$ had not registered for a course, 
and $17 \%$ reported dropping or withdrawing from a course, all at least once. Although in every case the sum of those who reported these outcomes "often" and "very often" amounted to less than $5 \%$ (see Table 1), those who reported working more hours per week were more likely to drop or withdraw from a course due to the cost of textbooks $[r(251)=.13, p=.04]$.

Thirty percent of respondents reported earning a poorer grade in a course because of textbook costs. These individuals were more likely to self-identify as a member of a visible minority group $\left[r_{p b}\left(25^{2}\right)=\right.$ $.14, p=.03]$, hold a student loan $\left[r_{p b}(305)=.14, p=.02\right]$, and be working more hours per week $[r(253)=.15, p=.02]$.

However, among those respondents who provided estimates of both their average grade across their undergraduate coursework and their interim grade in the current course, a repeated measures t-test showed that these estimates were not significantly different $[t(83)=-1.27, p=.21]$.

Table 1

Respondents' Ratings of the Frequency of Educational Outcomes that Result from Textbook Costs

\begin{tabular}{lcccccc}
\hline & & \multicolumn{4}{c}{ Percentage ratings } \\
\cline { 3 - 7 } Action & $n$ & Never & Rarely & Sometimes & Often & Often \\
\hline Taken fewer courses & 307 & 72.6 & 10.7 & 11.7 & 2.6 & 2.3 \\
Not registered for a specific course & 307 & 73.9 & 10.7 & 11.1 & 4.2 & 0.0 \\
Dropped or withdrawn from a course & 305 & 82.6 & 8.9 & 6.6 & 1.6 & 0.3 \\
Earned a poor grade & 307 & 70.4 & 13.0 & 11.7 & 3.9 & 1.0 \\
\hline
\end{tabular}

\section{Use of Open Textbooks}

A majority of respondents accessed their open textbook in only digital format(s), with $72 \%$ downloading a PDF file and 50\% reading it online using a computer. A minority of respondents reported accessing their open textbook using a smartphone (24\%), a tablet device (15\%), or an ereader (9\%). Of the $43 \%$ of respondents who obtained their open textbook in print format, $27 \%$ printed it at home (the vast majority of whom [79\%] printed pages or chapters as needed), $9 \%$ used a centralized provincial print-on-demand service, and $6 \%$ used a different professional printing service.

The mean respondent indicated that their course instructor encouraged them to read their open textbook between "occasionally" and "frequently" $[M=3.79(S D=1.12)$ on a 5-point Likert scale ranging from "never" to "always"]. Accordingly, respondents indicated that they spent just over 3-4 hours per week studying for their course $\left[M=2.32(S D=1.15)\right.$ where $2=3-4$ hours/week and $3=5^{-6}$ hours/week $]$ and completed over $60 \%$ of their weekly assigned readings $[M=3.65(S D=1.37)$ where 3 $=40-60 \%$ and $4=60-80 \%]$. The median respondent perceived that the overlap between textbook and lecture content was 50-75\%.

Respondents indicated that they read their open textbook before taking an exam between "sometimes" and "very often" $[M=3.76(S D=0.96)$ on a 5-point Likert scale ranging from "never" to "always"]. Overall, respondents reported studying for their course exams for an average of 9.28 hours $(S D=$ 8.11), starting an average of 5.78 days before each exam $(S D=4.13)$. The median respondent estimated that the proportion of exam questions drawn from their open textbook was 50-75\%. 


\section{Perceptions of Open Textbooks}

Sixty-three percent of respondents judged the overall quality of their open textbook to be above average or excellent, with an additional 33\% rating it as average. Only $3.5 \%$ of the sample rated their open textbook below average in quality (see Figure 4).

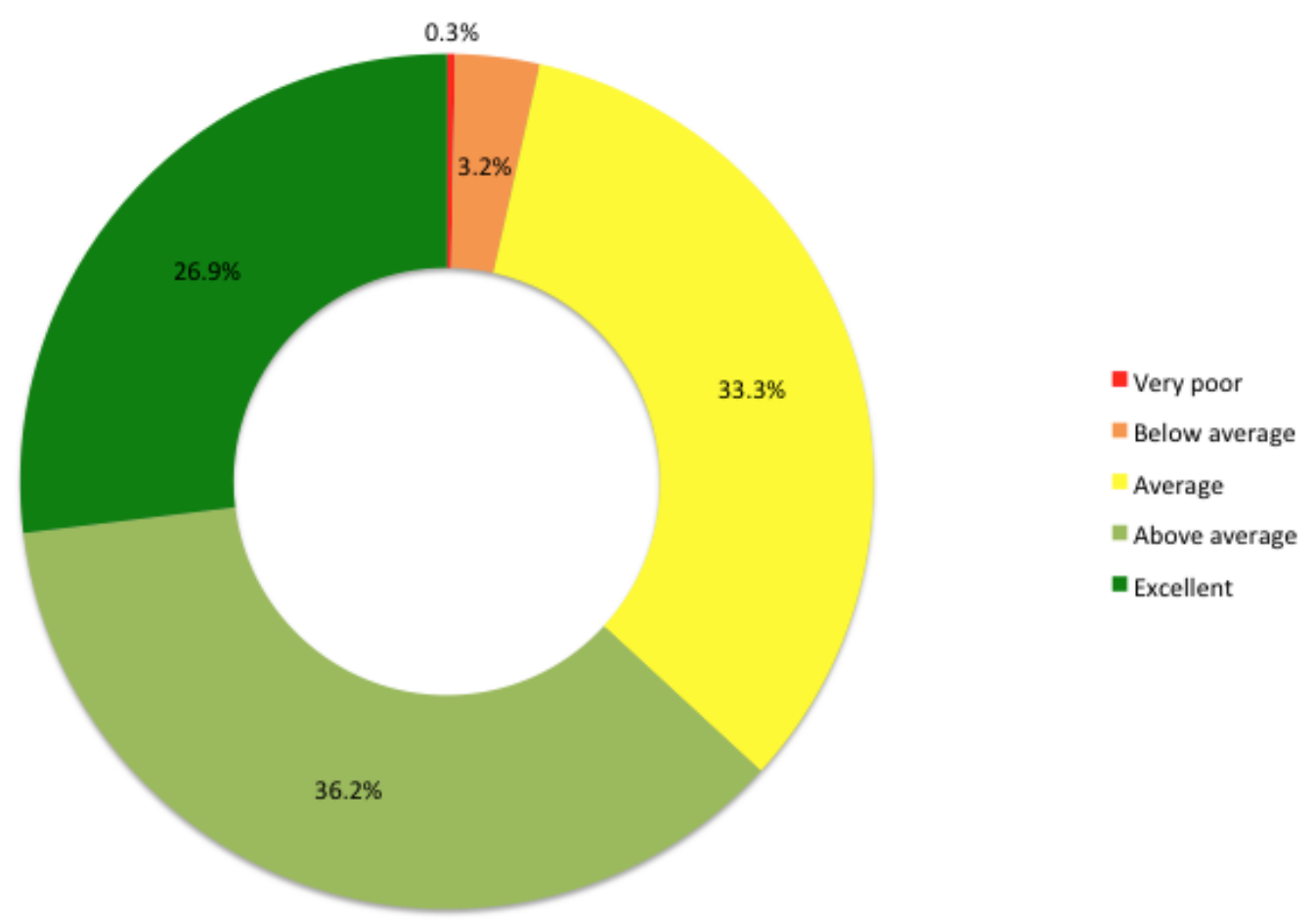

Figure 4. Respondents' perceptions of quality of their open textbook.

When asked to estimate what a fair price would be for their open textbook (regardless of what they paid), respondents' estimates ranged from $\$ 0-\$ 225$, with a mean of $\$ 63.45(S D=48.06)$. Interestingly, students who only used the free digital formats of their open textbook tended to estimate a higher fair price ( $M=\$ 66.74, S D=\$ 48.92)$ than students who printed their open textbook $(M=\$ 56.57, S D=\$ 46)$, although an independent samples t-test showed that this difference is not statistically significant $[t(131)=1.14, p=.26]$.

When asked to rate how important different features of their open textbook were to them, $70 \%$ of respondents rated "immediate access" as either "very important" or "absolutely essential." This was followed closely by "cost savings" (68\%), and then convenience and portability of the digital format (54\%), ability to print pages (41\%), ability to keep it forever (37\%), and ability to share it with others (34\%; see Table 2). 
Table 2

Respondents' Ratings of the Importance of the Features of their Open Textbook

\begin{tabular}{lcccccc}
\hline & & \multicolumn{5}{c}{ Percentage ratings } \\
\cline { 3 - 7 } & $n$ & $\begin{array}{c}\text { Not } \\
\text { important } \\
\text { at all }\end{array}$ & $\begin{array}{c}\text { Of little } \\
\text { importance }\end{array}$ & $\begin{array}{c}\text { Of average } \\
\text { importance }\end{array}$ & $\begin{array}{c}\text { Very } \\
\text { important }\end{array}$ & $\begin{array}{c}\text { Absolutely } \\
\text { essential }\end{array}$ \\
\hline Cost savings & 227 & 2.6 & 8.4 & 21.1 & 30.0 & 37.9 \\
Immediate access & 227 & 1.3 & 6.2 & 22.9 & 36.1 & 33.5 \\
Convenience /portability & 221 & 10.0 & 14.0 & 21.7 & 28.5 & 25.8 \\
Ability to print pages & 219 & 16.4 & 20.1 & 22.4 & 20.5 & 20.5 \\
Ability to keep it forever & 222 & 21.6 & 22.1 & 19.4 & 20.3 & 16.7 \\
Ability to share it with others & 209 & 17.2 & 22.5 & 26.8 & 17.2 & 16.3 \\
\hline
\end{tabular}

These ratings were supported by respondents' open-ended comments concerning what they liked about their open textbook. Using inductive semantic thematic analysis to identify emergent themes (Braun \& Clarke, 2006), 19 of the 44 comments referred to features that made their open textbook user friendly (whether in terms of portability, accessibility, or the ability to print or highlight the text), 12 comments referred to the cost savings associated with their open textbook, and nine comments referred to the content of their open textbook as being clear, concise, and mapped onto the course learning outcomes. Representative comments include the following:

It's portable and can be accessed at any computer. The problem of forgetting to bring the textbook to a study session or friend's house is a problem of the past. I can study anywhere at any time. I have downloaded it in a variety of format [sic] and so far I managed to fit my studying on the skytrain ride to work or even on my lunch hour without having to carry a heavy backpack with all my textbooks. It also helps with limiting the amount of things I have to carry around. I used to carry a backpack with 3 different textbooks and binders and it put a strain on the back. If only all courses used this format it would help not only financially but also physically.

I like being able to print it for cheap and that way I don't feel guilty about highlighting all over it. Also it is a lot lighter. If you forget it at home you have access to it on a computer.

I like the fact that they are accessible at all times and that the information we learn from the textbook is exactly what we are tested on in exams. All the information is useful in open textbooks and there are no chapters that we "skip."

It is compiled with only the necessary information for the course. Many courses do not include a number of sections out of textbooks and I find myself reading unnecessary content.

If cost were not a factor $44 \%$ of respondents would have preferred using their textbook in only print format, $41 \%$ would have preferred using both print and digital formats, and only $16 \%$ would have preferred using only digital format(s). Respondents who preferred using only the print format indicated that this preference was based on a desire to write in and highlight a print copy (85\%), etextbooks being inconvenient to read (64\%), difficult to navigate (60\%), incompatible with print disability solutions (11\%), and not having access to required technology to access e-textbooks (6\%). 
These ratings were supported by respondents' open-ended comments about what they disliked about their open textbook. Once again, inductive semantic thematic analysis was used to identify emergent themes. Of the 31 comments, 12 referred to issues with usability (e.g., requirement of internet access, inability to highlight, difficulty with reading on a screen, etc.), and eight referred to additional benefits of the print format (e.g., reduced distractibility, tangible reminder to complete readings, etc.). Representative comments include the following.

- "Reading on a screen is much less enjoyable than in paper, loss of access on occasion, reading on a screen makes absorbing information seem more difficult? Lots of distractions online."

- "I don't like the fact that you aren't able to highlight anything in PDF."

- "Need the internet to access so sometimes tough to study on road trips."

In addition, although not representative of the sample, one respondent commented thoughtfully here about a perceived positive relationship between textbook cost and use, while simultaneously noting that the notion of a textbook is itself a relic of a pre-digital age:

its [sic] a textbook. i feel that using a textbook in any form is an antiquated concept. especially when the internet exists. to be honest, i've never even looked at my open textbook. i've made more use of old fashioned textbooks that i've purchased. perhaps because they are tangible things, but its [sic] probably just because i spent so much money on them. a free textbook feels strangely irrelevant for some reason. more irrelevant than the other ones that is.

Finally, a majority of respondents (56\%) disagreed slightly or strongly with the statement "I would have preferred to purchase a traditional textbook for this course," with an additional $24 \%$ neither agreeing nor disagreeing with this statement (see Figure 5). 


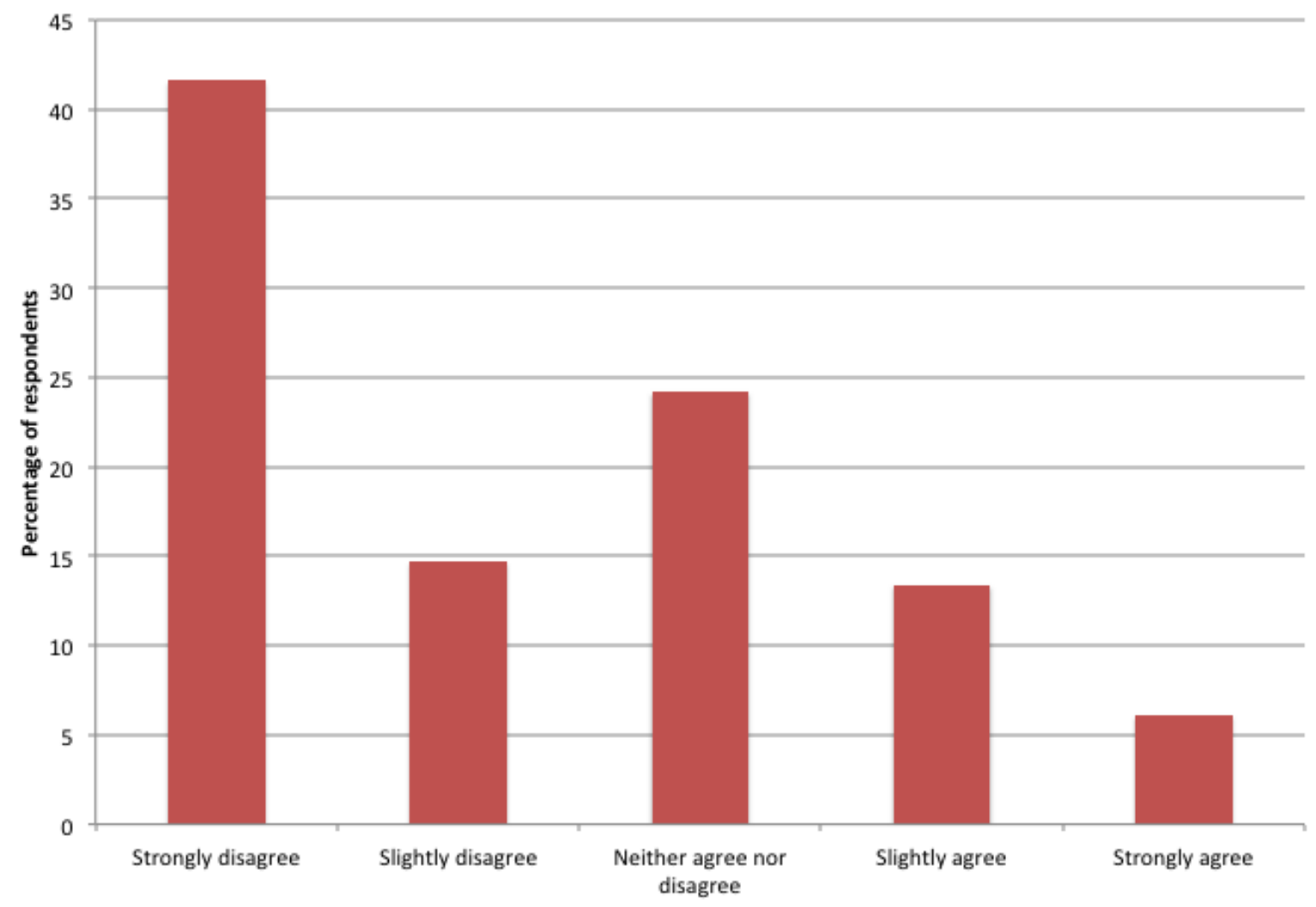

Figure 5. Respondents' degree of agreement with the statement "I would have preferred to purchase a traditional textbook for this course."

\section{Discussion}

The present study provides a snapshot of how Canadian post-secondary students obtain and access their required course textbooks. Whereas previous studies suggested that Canadian students spend approximately $\$ 350$ per semester on textbooks, the median respondent in our survey reported spending approximately $\$ 100$ less than this. Although this discrepancy could conceivably be a function of the median respondent being enrolled in only 7-9 courses over the previous 12 months, increases in the popularity of (less expensive) e-textbooks, or unconventional means of obtaining textbooks, the displaced cost of a single commercial textbook (represented by their assigned open textbook) itself serves as a sufficient explanation. Unfortunately, these cost savings were trumped by the average cost of "required" textbooks that were never used in respondents' classes (\$214-298), a distressing practice that respondents indicated they experience about half of the time.

The predicament of budget-conscious post-secondary students is laid especially bare by the fact that fewer than one in five respondents reported being unaffected by the cost of textbooks. Regrettably, it appears that the negative impact of textbook costs is disproportionately borne by economically disadvantaged students, including those holding a student loan and those working more hours per week. With a majority of respondents electing to purchase their textbooks from somewhere other than their campus store, nearly a third downloading their textbooks from the internet, and just over a quarter sharing a purchased textbook, it is also evident that revenue at campus stores from the sales of textbooks is in a (possibly irrevocable) state of decline. 
Overall, the proportions of students buying their textbooks from a source other than their campus store, buying used textbooks from their campus store, sharing textbooks, leasing e-textbooks, downloading textbooks from the internet, and reselling their textbooks were all reasonably similar to the proportions found by major U.S. surveys (e.g., Book Industry Study Group, 2013; Florida Virtual Campus, 2016). The same can be said for the number of "required" textbooks that were not actually used in respondents' classes. On the other hand, one noticeable difference from the U.S. context is in the lower proportion of respondents electing to rent textbooks. This trend has been previously anecdotally reported (e.g., Brownell, 2015) and may be traced to the relatively later introduction of textbook rental programs on Canadian campuses (Jerema, 2010).

In another contrast to U.S. research, a smaller proportion of respondents (although still a majority) reported not purchasing at least one of their required course textbooks due to cost, and an even smaller proportion reported doing so "often." A similar trend is seen with the choice to take fewer courses and to drop or withdraw from a course. A likely possible explanation for these differences is the greater financial pressure placed on U.S. post-secondary students, who face significantly higher tuition costs (US $\$ 11,487$ vs. C $\$ 5,998$ during the 2014-15 academic year; National Center for Education Statistics, 2015, Table 330.10; Statistics Canada, 2014). However, although these suboptimal choices are less prevalent among our sample, once again, they are disproportionately made by those who hold student loans and work the most. Indeed, one can easily conceive of a negative cycle wherein the need to work more hours in order to pay for tuition and textbooks necessitates taking fewer courses, an outcome that delays graduation and requires taking on more student loan debt. Alternatively, cash-strapped students might elect to do without one or more required textbooks. However, in this scenario it would not be surprising for them to perform more poorly (as was reported by nearly a third of respondents in the present study), an outcome that might necessitate repeating a course, once again resulting in a delayed graduation and the accumulation of more student loan debt.

Although the existing literature on how students access e-textbooks suggests that students are more likely to read e-textbooks online than to download a PDF file (deNoyelles, Raible, \& Seilhamer, 2015), this trend was reversed in the present study. Doubtless, the format in which respondents accessed their open textbook is likely to have been heavily influenced by the format in which it was distributed by their instructor (e.g., posting a PDF file to the learning management system). Unfortunately we did not collect data that would allow us to test this hypothesis.

Nearly half of respondents obtained a print copy of their open textbook. Although this is significantly higher than other estimates of the proportion of students who order print copies of open textbooks ( $10 \%$; Voorhis, 2016), these estimates typically point to the purchase of professionally printed and bound open textbooks whereas respondents in the present study were more likely to print chapters as needed at home. Nonetheless, this finding underscores that the ability to print open textbooks as and when a student desires is a valuable feature.

The amount of time that respondents reported spending studying per week for their course is comparable to the study habits of the median U.S. college freshman (Ruiz, Sharkness, Kelly, DeAngelo, \& Pryor, 2010). This is unsurprising, given that respondents' instructors generally encouraged them to read their open textbook and that the median respondent perceived that a majority of exam questions were derived from material covered in their open textbook. Taken 
together, this tentatively suggests that the adoption of an open textbook does not necessarily have a major influence on students' study habits.

Given the diversity in this study of courses, instructors, and assigned open textbooks, it might seem extraordinary for $96 \%$ of respondents to perceive the quality of their open textbook to be equal or superior to a commercial textbook. However, this result is quite consistent with the existing literature on student perceptions of OER (see Hilton, 2016). Relatedly, respondents estimated a mean fair price for their open textbook that was only slightly lower than the median amount they spent per course on commercial textbooks. On the one hand, this is heartening, given the frequent charge that dissonanceafflicted students may not value that which they are given for free (Festinger, 1957). On the other hand, these results might be better explained by research that shows that when a product is available free of cost, people react with an overly positive affective evaluation, which in turn produces an increased valuation of the product (Shampanier, Mazar, \& Ariely, 2007).

It is informative to regard the relative importance to students of the features of open textbooks. Immediate access and cost savings ranked at the top of respondents' list; however, it is worth noting that these two features are intertwined, as the principal reasons why students might delay obtaining their required textbooks are financial in nature (e.g., waiting for a student loan or determine whether the textbook is truly required). The tension between textbook costs and access is thrown into even sharper relief when one compares the features that respondents reported liking about open textbooks with their usual textbook purchasing behaviours. For instance, although a majority of respondents reported selling their used textbooks at the end of their courses, the majority also indicated that the ability to permanently retain their open textbook was desirable.

Respondents were almost three times as likely to indicate a preference (if cost were not a factor) for using only print textbooks than using only digital textbooks, with a majority citing an inability to annotate or highlight and difficulties with navigation as reasons for this preference. However, given that highlighting, annotation, searchability, and easy navigation are key features of modern etextbooks, this result may serve as yet another illustration of the myth of the so-called "digital native" (ECDL Foundation, 2014). In fact, this result is consistent with the literature on students' textbook format preferences, particularly in courses in which instructors do not model or use the features of etextbooks (e.g., highlighting, annotation, searchability, easy navigation; deNoyelles et al., 2015). In other words, low digital literacy (among both students and faculty) likely shapes preferences for textbook format.

Finally, given that four out of five respondents did not regret not purchasing a commercial textbook for their course, it appears that the benefits of open textbooks (cost savings, immediate access, convenience, portability, permanent retention, etc.) outweighed the costs (perceived inability to annotate or highlight, difficulty with navigation, etc.) in respondents' eyes.

\section{Limitations and Strengths}

This study possesses several limitations, beginning with the low survey response rate. While it is well known that online surveys tend to yield significantly lower response rates than paper surveys (e.g., Nulty, 2008), in this case there is insufficient information available about the distribution of the email invitation to precisely calculate the survey response rate. Related to this is the question of the representativeness of the obtained sample. Although more than three quarters of the sample consisted 
of students at teaching-intensive universities and colleges, this reflects patterns of course adoptions of open textbooks across the different types of institutions in British Columbia (BCcampus, 2016b). Within the institutions, however, it is unknown whether the faculty who chose to forward the email invitation to their students held more favourable impressions of the open textbook they had assigned than those faculty who chose not to forward the email invitation. Similarly, it is unknown whether the students who elected to complete the survey were those who held more favourable impressions of their assigned open textbook.

Other selection biases may also have influenced the composition of the sample. For example, previous research has found that student respondents of surveys are less likely than average be receiving financial aid (Porter \& Whitcomb, 2005). If this was the case in the present study it would likely result in underestimates of the negative impact of textbook costs. On the other hand, given that the survey was conducted online, it is possible that respondents self-selected based on their greater access to and comfort with digital platforms. If this were true it would likely result in inflated perceptions of the benefits of e-textbooks. It would also explain the very low proportion of respondents who indicated that lack of access to required technology was reason for their preference for print textbooks.

Finally, although the respondents remained anonymous when completing the survey, as a self-report instrument the survey included questions that are susceptible to biases such as those related to social desirability (e.g., hours spent studying per week), reconstructive memory (e.g., amount spent on textbooks during the last 12 months), and introspective ability (e.g., the relative importance of features of open textbooks). In addition, several of the survey questions utilized an ordinal response scale (e.g., hours worked per week, credits completed, etc.) where an interval scale would have yielded more precise information. Finally, additional questions that would have yielded useful information (e.g., how their instructor distributed the open textbook, whether they were less likely to purchase a textbook for a required vs. elective course) were not included. Each of these weaknesses provides direction to future research in this area.

Despite these limitations, this survey represents several firsts. It is the first to investigate the impact of textbooks costs on Canadian students' educational choices (including the practice of downloading textbooks from the internet) as well as the first to investigate the use and perceptions of Canadian students who have been assigned open textbooks. To our knowledge no other published study has investigated the monetary value that students place on open textbooks, whether students value the permissions to retain and redistribute open textbooks, and whether, after a few months of using an open textbook, they would indicate a preference for commercial textbooks.

\section{Conclusion}

The high cost of textbooks has a measurable and negative impact on the educational choices and outcomes of post-secondary students in British Columbia. Students assigned open textbooks perceive these resources to be of generally high quality and value the cost savings, immediate access, portability, and other benefits they confer.

Future research should continue to investigate the perceptions, use, and impact of open textbooks and other OER outside of the U.S. post-secondary context and especially to attempt to replicate evidence 
of the disproportionate impact of high textbook costs on economically disadvantaged students. Several questions raised in this study also merit investigation, including the cumulative effects of textbook costs on time-to-degree and student loan debt accrual, the influence of assigned textbook format on textbook preferences and usage, and the impact of the interaction between instructor characteristics and textbook characteristics on student outcomes.

If future success hinges on access to information, open textbooks are an important means of ensuring a more even distribution.

\section{Acknowledgements}

This research was funded by a Katalyst grant from Kwantlen Polytechnic University to Rajiv S. Jhangiani. The authors are grateful to Rebecca Deutschmann for her assistance with the preparation of the IRB application, data collection, and manuscript preparation, and to Clint Lalonde, Amanda Coolidge, and Lauri Aesoph at BCcampus for their assistance with participant recruitment.

\section{References}

BCcampus. (2016a). The project. Retrieved from https://open.bccampus.ca/the-project/

BCcampus. (2016b). Open textbook stats. Retrieved from https://open.bccampus.ca/open-textbookstats/

Bliss, T. J., Hilton, J., III., Wiley, D., \& Thanos, K. (2013). The cost and quality of open textbooks: Perceptions of community college faculty and students. First Monday, 18(1). doi:10.5210/fm.v18i1.3972

Bliss, T., Robinson, T. J., Hilton, J., III., \& Wiley, D. (2013b). An OER COUP: College teacher and student perceptions of open educational resources. Journal of Interactive Media in Education, 17(1), 1-25. http://dx.doi.org/10.5334/2013-04

Book Industry Study Group. (2013). Student attitudes toward content in higher education. Book Industry Study Group, 4(1). New York: Author.

Braun, V. \& Clarke, V. (2006) Using thematic analysis in psychology. Qualitative Research in Psychology, 3(2), 77-101. http://dx.doi.org/10.1191/1478088706qpo63oa

Brownell, C. (2015, September 4). Fighting big textbook: How students are trying to save money as prices keep going up. Financial Post. Retrieved from http://business.financialpost.com/personal-finance/young-money/fighting-big-textbookhow-students-are-trying-to-save-money-as-prices-keep-going-up

Creative Commons. (2015). State of the commons. Retrieved from https://stateof.creativecommons.org/2015/ 
Delimont, N., Turtle, E. C., Bennett, A., Adhikari, K., \& Lindshield, B. L. (2016). University students and faculty have positive perceptions of open/alternative resources and their utilization in a textbook replacement initiative. Research in Learning Technology, 24. Retrieved from http://www.researchinlearningtechnology.net/index.php/rlt/article/view/29920 http://dx.doi.org/10.3402/rlt.v24.29920

deNoyelles, A., Raible, J., \& Seilhamer, R. (2015, July 6). Exploring students' e-textbook practices in higher education. Educause Review. Retrieved July 20, 2016, from http://er.educause.edu/articles/2015/7/exploring-students-etextbook-practices-in-highereducation

ECDL Foundation. (2014). The fallacy of the 'digital native': Why young people need to develop their digital skills. Retrieved from http://www.ecdl.org/media/TheFallacyofthe'DigitalNative'PositionPaper1.pdf

Feldstein, A., Martin, M., Hudson, A., Warren, K., Hilton, J., III., \& Wiley, D. (2012). Open textbooks and increased student access and outcomes. European Journal of Open, Distance and ELearning, 2, 1-9. Retrieved from http://files.eric.ed.gov/fulltext/EJ992490.pdf

Festinger, L. (1957). A theory of cognitive dissonance (Vol. 2). Stanford, CA: Stanford University Press.

Financial Consumer Agency of Canada. (2014). Budget for student life-How much will your postsecondary cost? Retrieved from: http://www.fcacacfc.gc.ca/Eng/forConsumers/lifeEvents/payingPostSecEd/Pages/Budgetfo-Unbudget.aspx

Florida Virtual Campus. (2016). 2016 student textbook and course materials survey. Retrieved from https://florida.theorangegrove.org/og/items/3a65c507-2510-42d7-814c-ffdefd394b6c/1/

Gil, P., Candelas, F., Jara, C., Garcia, G., \& Torres, F. (2013). Web-based OERs in computer networks. International Journal of Engineering Education, 29(6), 1537-1550.

Hall, A. (2013). It's time to buy those god-awful textbooks! The Carillon. Retrieved from http://www.carillonregina.com/its-time-to-buy-those-god-awful-textbooks/

Hill, P. (2015, November 8). Bad data can lead to bad policy: College students don't spend $\$ 1,200+$ on textbooks [Blog post]. Retrieved from http://mfeldstein.com/bad-data-can-lead-to-badpolicy-college-students-dont-spend-1200-on-textbooks/

Hilton, J., III. (2016). Open educational resources and college textbook choices: A review of research on efficacy and perceptions. Educational Technology Research and Development, 64(4), 573590. doi:10.1007/s11423-016-9434-9

Hilton, J. L., III., Fischer, L., Wiley, D., \& William, L. (2016). Maintaining momentum toward graduation: OER and the course throughput rate. International Review of Research in Open and Distance Learning, 17(6). http://dx.doi.org/10.19173/irrodl.v17i6.2686 
Hilton, J., III., Gaudet, D., Clark, P., Robinson, J., \& Wiley, D. (2013). The adoption of open educational resources by one community college math department. The International Review of Research in Open and Distance Learning, 14(4), 37-50. Retrieved from http://www.irrodl.org/index.php/irrodl/article/view/1523/2652

Hilton, J., III., \& Laman, C. (2012). One college's use of an open psychology textbook. Open Learning, 27(3), 265-272. http://dx.doi.org/10.1080/02680513.2012.716657

Jerema, C. (2010, September 15). How to save money on textbooks-rent them. Maclean's. Retrieved from http://www.macleans.ca/education/uniandcollege/how-to-save-money-on-textbooksrent-them/

Jhangiani, R. S., Pitt, R., Hendricks, C., Key, J., \& Lalonde, C. (2016). Exploring faculty use of open educational resources at British Columbia post-secondary institutions. Victoria, BC: BCcampus.

Justice Laws Website. (2008). Book importation regulations. Retrieved from http://lawslois.justice.gc.ca/eng/regulations/sor-99-324/FullText.html

Lepore, J. (2013, September 18). Downloading textbooks thrifty but questionable trend among students. CTV News. Retrieved from http://www.ctvnews.ca/sci-tech/downloadingtextbooks-thrifty-but-questionable-trend-among-students-1.1459621

Lindshield, B., \& Adhikari, K. (2013). Online and campus college students like using an open educational resource instead of a traditional textbook. Journal of Online Learning \& Teaching, 9(1), 1-7. Retrieved from http://jolt.merlot.org/volgno1/lindshield 0313.htm

National Association of College Stores. (2016). Key findings report: Student watch 2015-16 academic year. Retrieved from

http://www.nacs.org/Portals/NACS/Uploaded Documents/PDF/Research/IND.022.07.16 SW KeyFindings.pdf

National Center for Education Statistics. (2015). Digest of education statistics. Retrieved from https://nces.ed.gov/programs/digest/current tables.asp

Nulty, D. D. (2008). The adequacy of response rates to online and paper surveys: What can be done? Assessment \& Evaluation in Higher Education, 33(3), 301-314. doi:10.1080/02602930701293231

Petrides, L., Jimes, C., Middleton-Detzner, C., Walling, J., \& Weiss, S. (2011). Open textbook adoption and use: Implications for teachers and learners. Open Learning, 26(1), 39-49. doi:10.1080/02680513.2011.538563

Pitt, R., Ebrahimi, N., McAndrew, P., \& Coughlan, T. (2013). Assessing OER impact across organisations and learners: Experiences from the Bridge to Success project. Journal of Interactive Media in Education, 3(17). doi:10.5334/2013-17 
Porter, S. R., \& Whitcomb, M. E. (2005). Non-response in student surveys: The role of demographics, engagement and personality. Research in Higher Education, 46(2), 127-152. doi:10.1007/s11162-004-1597-2

Ruiz, S., Sharkness, J., Kelly, K., DeAngelo, L., \& Pryor, J.H. (2010). Findings from the 2009 administration of the Your First College Year (YFCY): National aggregates. Los Angeles: Higher Education Research Institute, UCLA.

Shampanier, K., Mazar, N., \& Ariely, D. (2007). Zero as a special price: The true value of free products. Marketing Science, 26(6), 742-757. doi:10.1287/mksc.1060.0254

Statistics Canada. (2014). Undergraduate tuition fees for full time Canadian students, by discipline, by province (Canada). Retrieved from http://www.statcan.gc.ca/tables-tableaux/sumsom/lo1/cst01/educ50a-eng.htm

Studentawards Inc. \& Stepwise Research (2009, May). How college and university students and faculty think about course materials. Retrieved from http://pubcouncil.ca/textbookoptions/Faculty\%20\%20Student\%20Research\%20Report\%20V2.pdf

Student Monitor. (2016). Textbooks: Key findings Spring 2016. Retrieved from http://www.studentmonitor.com/s16/textbooks.pdf

U.S. Bureau of Labor Statistics. (2016, September 12). Consumer price index-all urban consumers: College textbooks. Retrieved from http://www.bls.gov/data/

Usher, A. (2015, February 26). Data on textbook costs [Blog post]. Retrieved from http://higheredstrategy.com/data-on-textbook-costs/

Voorhis, D. (2016, August 17). Your next college textbook may be free. The Wichita Eagle. Retrieved from http://www.dolphnsix.com/news/809254/your-next-college-textbook-free

Wallace, K. (2009, January 10). Textbook piracy thriving around city's campuses. Toronto Star. Retrieved from https://www.thestar.com/news/gta/2009/01/10/textbook_piracy thriving around citys_c ampuses.html

Wiley, D., Bliss, T. J., \& McEwen, M. (2014). Open educational resources: A review of the literature. In J. M. Spector, M. D., Merrill, J. Elen, \& M. J. Bishop. (eds.), Handbook of research on educational communications and technology (pp. 781-789). New York: Springer.

Wiley, D., Williams, L., DeMarte, D., \& Hilton, J. (2016). The Tidewater Z-Degree and the INTRO model for sustaining OER adoption. Education Policy Analysis Archives, 24(41).

http://dx.doi.org/10.14507/epaa.24.1828 


\section{Notes}

1. The BCOTP was launched in October 2012 and charged by the Ministry of Advanced Education with making available openly-licensed textbooks in the 40 highest-enrolled academic subject areas. Later, this focus was expanded to include open textbook for trades, technology, and skills-based training (BCcampus, 2016a). As of September 2016, there are 163 open textbooks available in the project catalog (see open.bccampus.ca), with 596 known course adoptions and a collective savings to students of over \$2.2 million (BCcampus, 2016b).

2. An additional 21 respondents partially completed the survey. These data are excluded from this report.

\section{Athabasca}

University

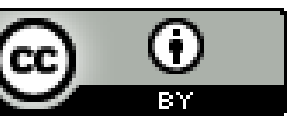

